\title{
Efficient clinical application of percutaneous cardiopulmonary support for perioperative management of a huge anterior mediastinal tumor
}

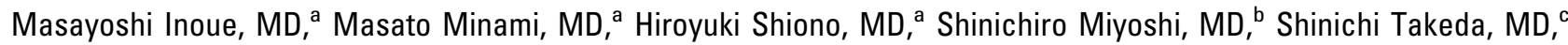
Mitsunori Ohta, MD, ${ }^{d}$ Masashi Goto, MD, ${ }^{a}$ Hiroshi Takano, MD, ${ }^{a}$ Yoshiki Sawa, MD, ${ }^{a}$

and Meinoshin Okumura, MD, ${ }^{\mathrm{a}}$ Tochigi, Japan

耳 erein we summarize our experience with 4 patients who had huge tumors that compressed mediastinal neighboring organs. Patient findings are summarized in Table 1, with computed tomographic (CT) images shown in Figure 1.

\section{Clinical Summary}

PATIENT 1. The patient was referred to our hospital with chest pain. Chest radiography and CT (Figure 1, A) images revealed a mediastinal mass $14 \mathrm{~cm}$ in diameter that was compressing the right main pulmonary artery (PA) and left main bronchus. Serum $\beta$-human chorionic gonadotropin $(\beta$-HCG) was $0.8 \mathrm{ng} / \mathrm{mL}$ (cutoff $<0.2 \mathrm{ng} / \mathrm{mL}$ ), whereas the $\alpha$-fetoprotein (AFP) level was within the normal limit $(<5 \mathrm{ng} / \mathrm{mL})$. We began performance of an incisional biopsy under general anesthesia. During the operation, ventilation insufficiency with severe hypoxemia occurred, and fiberoptic bronchoscopy revealed a left bronchial occlusion. After emergency application of percutaneous cardiopulmonary support (PCPS; Capiox emergency bypass system; Terumo, Tokyo, Japan), we performed PA tomography and found a total occlusion of the right PA. Thus, mediastinal compression by the huge tumor induced a complete ventilation-perfusion imbalance after general anesthesia with muscular relaxation. We performed an emergency tumor extirpation.

PATIENT 2. A patient with a testicular tumor associated with intrathoracic metastases was treated with a right high orchiectomy followed by chemotherapy in the department of urology. After normalization of serum AFP (maximum $1265 \mathrm{ng} / \mathrm{mL}$ ) and HCG (maximum $7 \mathrm{ng} / \mathrm{mL}$ ), we attempted a metastasectomy of the mediastinal tumor, which was causing bronchial stenosis (Figure 1, B). Ventilation insufficiency was anticipated during the induction of

aFrom the Division of Thoracic and Cardiovascular Surgery, Department of Surgery (E1), Osaka University Graduate School of Medicine, ${ }^{\mathbf{a}}$ Department of Thoracic Surgery, Toneyama National Hospital, ${ }^{\text {b }}$ Department of Thoracic Surgery, Kinki Chuo Chest Medical Center, ${ }^{c}$ and Department of Cardio Thoracic Surgery, Dokkyo University School of Medicine, ${ }^{\mathrm{d}}$ Tochigi, Japan.

Received for publication Oct 18, 2005; revisions received Nov 10, 2005; accepted for publication Nov 16, 2005.

Address for reprints: Masayoshi Inoue, MD, PhD, Division of Thoracic and Cardiovascular Surgery, Department of Surgery (E1), Osaka University Graduate School of Medicine, 2-2 Yamadaoka Suita-city, Tochigi, 5650871, Japan (E-mail: masa@surg1.med.osaka-u.ac.jp).

J Thorac Cardiovasc Surg 2006;131:755-6

$0022-5223 / \$ 32.00$

Copyright $\odot 2006$ by The American Association for Thoracic Surgery doi:10.1016/j.jtcvs.2005.11.023
TABLE 1. Patient data

\begin{tabular}{|c|c|c|c|c|}
\hline Patient & $\begin{array}{c}\text { Age }(y) / \\
\text { sex }\end{array}$ & Diagnosis & Operation mode & Outcome \\
\hline 1 & 19/male & Seminoma & $\begin{array}{l}\text { Incisional biopsy } \\
\text { Emergency } \\
\text { PCPS } \\
\text { Extirpation } \\
\text { SVC } \\
\quad \text { reconstruction }\end{array}$ & $\begin{array}{l}7 \text { y, alive } \\
\text { Disease } \\
\text { free }\end{array}$ \\
\hline 2 & 27/male & $\begin{array}{l}\text { Yolk sac tumor } \\
\text { Pulmonary } \\
\text { metastasis }\end{array}$ & $\begin{array}{l}\text { Extirpation } \\
\text { Right lower } \\
\text { lobectomy } \\
\text { PCPS }\end{array}$ & $\begin{array}{l}3 \text { y, alive } \\
\text { Disease } \\
\text { free }\end{array}$ \\
\hline 3 & 24/male & Yolk sac tumor & $\begin{array}{l}\text { Incisional biopsy } \\
\text { Emergency } \\
\text { extirpation } \\
\text { Right middle } \\
\text { lobectomy }\end{array}$ & $\begin{array}{l}2 \text { y, alive } \\
\text { Disease } \\
\text { free }\end{array}$ \\
\hline 4 & $15 /$ male & Teratocarcinoma & $\begin{array}{l}\text { Extirpation } \\
\text { PCPS }\end{array}$ & $\begin{array}{c}1 \mathrm{y}, \text { alive } \\
\text { Disease } \\
\text { free }\end{array}$ \\
\hline
\end{tabular}

PCPS, Percutaneous cardiopulmonary support; $S V C$, superior vena cava.

general anesthesia; therefore, we initiated PCPS with left axillary artery and right femoral vein cannulation. Thereafter, we safely resected the mediastinal tumor.

PATIENT 3. Patient 3 presented with chest pain and a fever. Chest radiograph and CT images revealed a huge mass that occupied one fourth of the right thorax. Serum AFP and HCG concentrations were increased to 10,100 and $490 \mathrm{ng} / \mathrm{mL}$, respectively. We performed an incisional biopsy under infiltration anesthesia for histologic diagnosis. During the biopsy, a portion of the tumor had fallen into the thorax, and tracheal intubation was required. However, after several needle biopsy attempts, mechanical ventilation became impossible. Fiberoptic bronchoscopy showed an airway obstruction at the level of the carina, and CT demonstrated tumor expansion caused by an intratumorous hemorrhage (Figure 1, C). The patient was placed in a hemi-left upside position, and the airway obstruction was released; then emergency extirpation of the tumor was performed.

PATIENT 4. A student with orthopnea was referred to our hospital, and our CT found a heterogeneous mediastinal tumor 17 $\mathrm{cm}$ in diameter (Figure 1,D). Squamous cell carcinoma and carcinoembryonic antigen levels were increased to $14 \mathrm{ng} / \mathrm{mL}$ (cutoff $<2 \mathrm{ng} / \mathrm{mL}$ ) and $6 \mathrm{ng} / \mathrm{mL}$ (cutoff $<5 \mathrm{ng} / \mathrm{mL}$ ), respectively. Chemotherapy was administered under the diagnosis of a malig- 
A

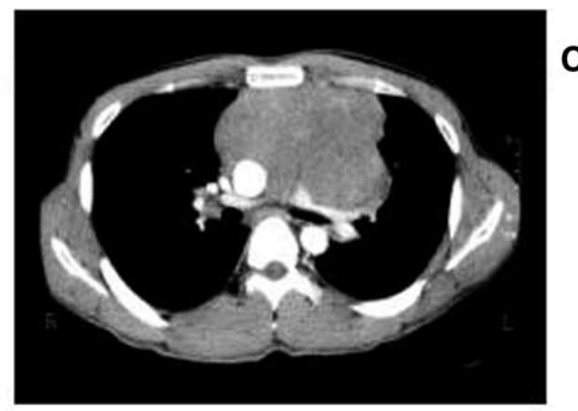

B

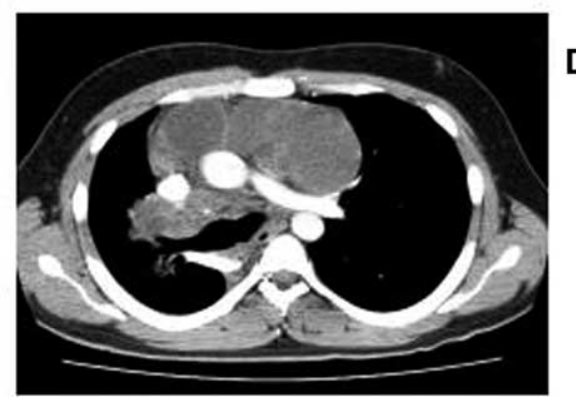

C
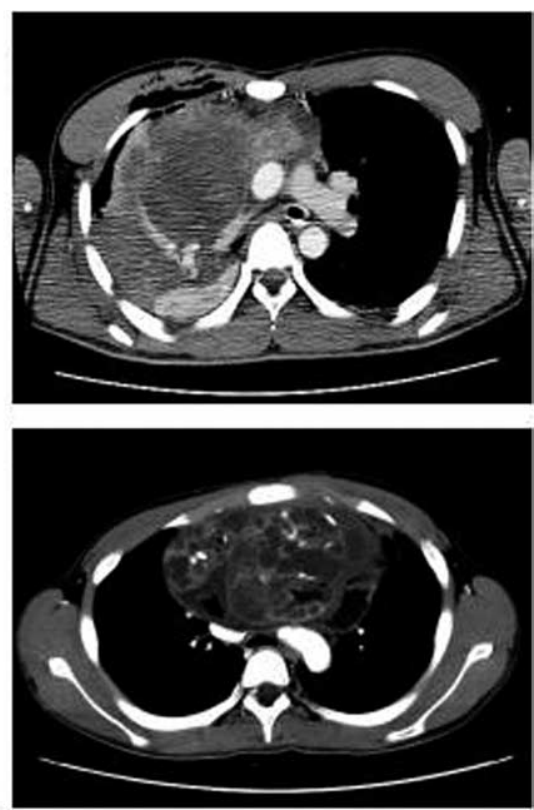

Figure 1. A, Patient 1: the right main PA and left main bronchus are seen compressed by an anterior mediastinal tumor. B, Patient 2: a metastatic tumor surrounding the great vessels is shown causing bronchial stenosis. C, Patient 3: emergency CT image taken after a needle biopsy revealing an intratumorous hemorrhage causing ventilation insufficiency. D, Patient 4: an anterior huge mass is seen compressing the left main bronchus and right main PA. The content was heterogeneous and consisted of cystic and calcified portions.

nant teratoma on the basis of the imaging and tumor marker results. The symptoms improved after 1 course; however, the tumor was not smaller and continued to compress the left main bronchus and right main PA. We performed tumor extirpation by using the assistance of PCPS with general anesthesia to prevent hypoxemia. PCPS was initiated with right femoral venous and arterial cannulation under infiltration anesthesia, with the patient in a semi-Fowler position. Cardiopulmonary support was sustained until the tumor was dissected from the neighboring mediastinal tissue, and complete resection was achieved without an intraoperative event.

\section{Discussion}

A huge anterior mediastinal tumor can obstruct the great vessels or respiratory tract during general anesthesia. ${ }^{1-5} \mathrm{We}$ documented the 4 patients with huge tumors to emphasize the usefulness of PCPS. According to our experience with patient 1, we used PCPS at the time of the induction of general anesthesia in patients 2 and 4, and the resections were performed uneventfully. As for patient 3, we did not use the assistance of PCPS for the biopsy under infiltration anesthesia. However, during the biopsy procedure, general anesthesia with tracheal intubation became required because intratumorous hemorrhage caused ventilatory insufficiency.

When acute ventilatory insufficiency occurs during an incisional biopsy of a huge mass, changing the position of the patient should be considered as an option to release mediastinal oppression caused by the tumor. We also recommend placing PCPS on standby, because general anesthesia with a muscle relaxant may be required and could make the airway obstruction worse. Further, PCPS should be indicated at the induction of general anesthesia for resection of a huge mediastinal tumor that causes airway compression. We consider that perioperative fatal complications can be avoided with the use of PCPS during surgical intervention for a huge anterior mediastinal tumor.

\section{References}

1. Bitter D. Respiratory obstruction associated with induction of general anesthesia in a patient with mediastinal Hodgkin's disease. Anesth Analg. 1975;59:399-403.

2. Tonnesen AS, Davis F. Superior vena caval and bronchial obstruction during anesthesia. Anesthesiology. 1976;45:91-2.

3. Wilson RF, Steiger Z, Jacob J, Sison OS, Holsey C. Temporal partial cardiopulmonary bypass during emergency operative management of near total tracheal occlusion. Anesthesiology. 1984;61:103-5.

4. Bray RJ, Fernandes FJ. Mediastinal tumour causing airway obstruction in anaesthetised children. Anaesthesia. 1982;37:571-5.

5. Takeda S, Miyoshi S, Omori K, Okumura M, Matsuda H. Surgical rescue for life-threatening hypoxemia caused by a mediastinal tumor. Ann Thorac Surg. 1999;68:2324-6. 